\title{
Biocatalytic Aldol Addition of Simple Aliphatic Nucleophiles to Hydroxyaldehydes
}

\author{
Raquel Roldán, ${ }^{\dagger}$ Karel Hernandez, ${ }^{\dagger}$ Jesús Joglar, $^{\dagger}$ Jordi Bujons, ${ }^{\dagger}$ Teodor Parella, ${ }^{\ddagger 0}$
}

Israel Sánchez-Moreno, ${ }^{\S}$ Virgil Hélaine, ${ }^{\S}$ Marielle Lemaire, ${ }^{\S}$ Christine Guérard-Hélaine, ${ }^{\S}$

Wolf-Dieter Fessner, ${ }^{\perp}$ and Pere Clapés ${ }^{*}, \dagger[0$

${ }^{\dagger}$ Biological Chemistry Department, Instituto de Química Avanzada de Cataluña IQAC-CSIC, Jordi Girona 18-26, 08034 Barcelona, Spain

${ }^{\ddagger}$ Servei de Ressonància Magnètica Nuclear, Universitat Autònoma de Barcelona, 08193 Bellaterra, Spain

${ }^{\S}$ University Clermont Auvergne, CNRS, SIGMA Clermont, Institut de Chimie de Clermont-Ferrand, 63000 Clermont-Ferrand, France

${ }^{\perp}$ Institut für Organische Chemie und Biochemie, Technische Universität Darmstadt, Alarich-Weiss-Str. 4, D-64287 Darmstadt, Germany

\section{Supporting Information}

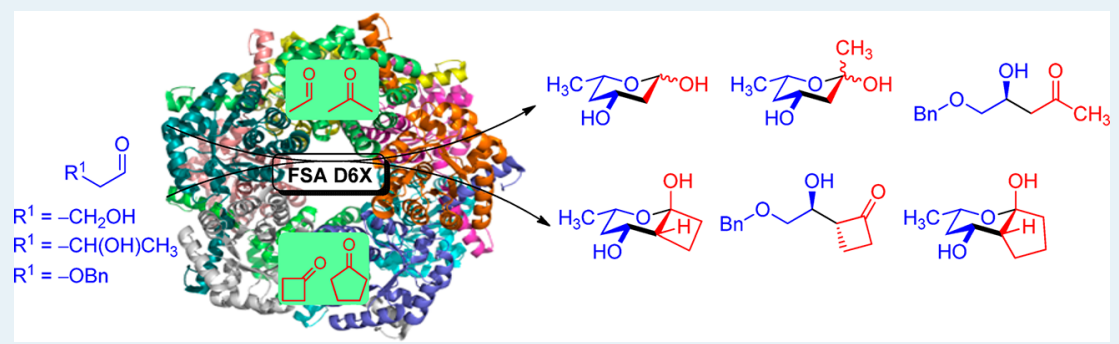

ABSTRACT: Asymmetric aldol addition of simple aldehydes and ketones to electrophiles is a cornerstone reaction for the synthesis of unusual sugars and chiral building blocks. We investigated D-fructose-6-phosphate aldolase from E. coli (FSA) D6X variants as catalysts for the aldol additions of ethanal and nonfunctionalized linear and cyclic aliphatic ketones as nucleophiles to nonphosphorylated hydroxyaldehydes. Thus, addition of propanone, cyclobutanone, cyclopentanone, or ethanal to 3hydroxypropanal or $(S)$ - or $(R)$-3-hydroxybutanal catalyzed by FSA D6H and D6Q variants furnished rare deoxysugars in 8$77 \%$ isolated yields with high stereoselectivity ( $97: 3 \mathrm{dr}$ and $>95 \% e e)$.

KEYWORDS: biocatalysis, aldol reaction, aldolases, asymmetric catalysis, deoxysugars, carbon-carbon bond formation, enzyme engineering

\section{INTRODUCTION}

Crossed aldol additions of simple aliphatic aldehydes and ketones to electrophiles are important transformations in organic synthesis. The asymmetric version enables access to a range of interesting unusual carbohydrates and important chiral building blocks for the preparation of naturally occurring and synthetic bioactive products, including pharmaceuticals. $^{1-8}$ These conversions are, however, cumbersome because of notorious side reactions such as polymerization, homo aldolization, and aldol condensation, as well as low stereoselectivity. ${ }^{6,9,10}$ Enzymatic C-C bond formation mediated by aldolases is a very attractive alternative for this purpose, because of its unparalleled high stereoselectivity, avoidance of extensive protective group chemistry, and operation under mild conditions. ${ }^{11-14}$ A typical disadvantage of these enzymes is their rather narrow scope of acceptable nucleophilic substrates, whereas they tolerate a broad variety of aldehydes as the electrophilic components.
The class I D-fructose-6-phosphate aldolase from E. coli (FSA, EC 4.1.2.-) and variants with minimal mutations on selected residues within its active site, showed an unprecedented tolerance toward a large structural variety of nucleophilic and electrophilic substrates. ${ }^{15-30}$ This unveiled its extraordinary malleability beyond the boundaries of currently known aldolases. Furthermore, we recently uncovered that ethanal, propanone, butanone, and cyclopentanone are acceptable as nucleophilic components for wild-type FSA and its $\mathrm{D} 6 \mathrm{H}$ variant when $\mathrm{L}$ - and D-glyceraldehyde-3-phosphate (G3P) are the electrophiles. ${ }^{31}$ Nevertheless, the corresponding nonphosphorylated analogues reacted sluggishly or failed to furnish an aldol adduct.

Received: June 27, 2018

Revised: $\quad$ August 7, 2018

Published: August 8, 2018 
In this work, we show that engineered variants FSA D6 $\mathrm{X}^{32}$ catalyze aldol additions of ethanal (1a), linear $(\mathbf{1} \mathbf{b}-\mathbf{d})$, and cyclic $(\mathbf{1} \mathbf{e}-\mathbf{g})$ simple aliphatic ketones to nonphosphorylated hydroxyaldehyde derivatives $(\mathbf{2 a - c})$ (Figure 1$)$, expanding the synthetic utility to rare and unusual sugar derivatives as well as related chiral building blocks.

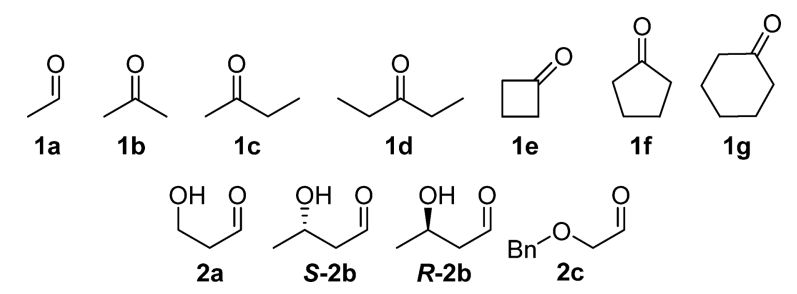

Figure 1. Panel of selected nucleophiles $(\mathbf{1} \mathbf{a}-\mathbf{g})$ and electrophiles $(2 a-c)$.

\section{RESULTS AND DISCUSSION}

Models of FSA wild-type in complex with the K85-D-fructose6-phosphate (Fru6P) imine and the K85-dihydroxyacetone (DHA) enamine plus D-G3P show that these substrate intermediates can establish direct contacts with Y131, N28, and D6 residues of the active site (Figure 2). These models suggested that residue D6 can interact via hydrogen-bonding

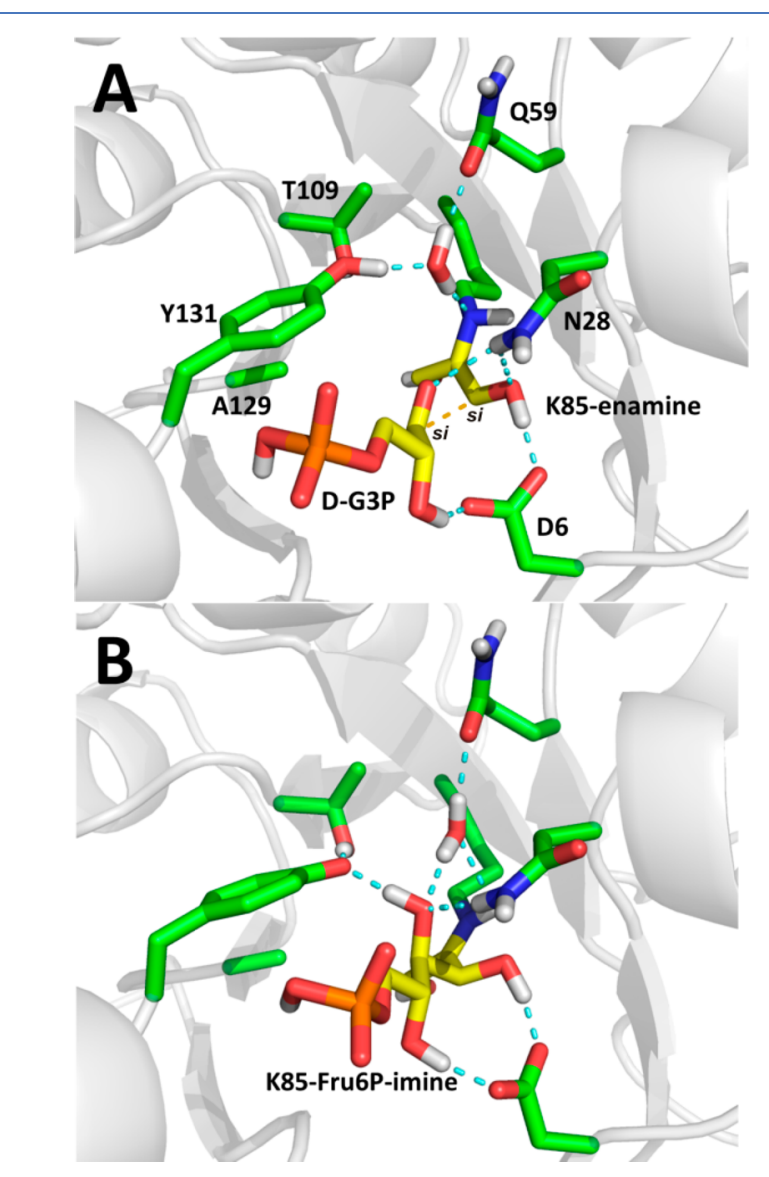

Figure 2. Molecular models of FSA-bound DHA-enamine/D-G3P (A) and Fru6P-imine (B) intermediates. In both cases, the D6 residue is forming two hydrogen bonds with the $\mathrm{C} 2$ hydroxyl group of the D-G3P and the hydroxymethyl group of the DHA (A), or the corresponding $\mathrm{C} 3$ and $\mathrm{C} 5$ hydroxyl groups of Fru6P (B). both with the $\mathrm{CH}_{2} \mathrm{OH}$ group of nucleophiles such as DHA and with the $\mathrm{C} 2-\mathrm{OH}$ of $\mathrm{D}-\mathrm{G} 3 \mathrm{P}$, thereby influencing both the nucleophile and electrophile selectivity. ${ }^{33-35}$ To break the hydrogen bonding pattern of D6, this residue was targeted for site directed mutagenesis to obtain FSA variants with tolerance toward aldol additions of $\mathbf{1 a}$ and ketones $\mathbf{1} \mathbf{b}-\mathbf{g}$ as nucleophiles to nonphosphorylated hydroxyaldehydes. Thus, individual FSA D6X variants were produced, where $\mathrm{X}=$ hydrophobic (A and $\mathrm{L})$, polar charged (E and $\mathrm{H})$, or polar uncharged $(\mathrm{N}, \mathrm{Q}, \mathrm{S}$, and T) amino acids. Variants L107A, L163A, and A165G, which had been identified in earlier studies to benefit the nucleophile and electrophile substrate tolerance, were also screened. ${ }^{16,22}$

In the standard aldol addition of DHA to D,L-G3P, only the activity of FSA D6N was found to be comparable to that of FSA wild-type $\left(45.4 \pm 0.1 \mathrm{U} \mathrm{mg}^{-1}\right.$ vs $46.0 \pm 0.1 \mathrm{U} \mathrm{mg}^{-1}$, respectively). Indeed, asparagine is isosteric to aspartate and able to establish similar hydrogen bonding interactions, which explains why no dramatic changes on the activity were observed. On the other hand, for all other D6X replacements, only very low activity was detected (between $0.72 \pm 0.01$ to $\left.0.03 \pm 0.01 \mathrm{U} \mathrm{mg}^{-1}\right)($ Table S2 in SI), confirming the critical importance of aspartate for binding of hydroxylated nucleophiles.

We began testing the panel of ketone nucleophiles $\mathbf{1 b}-\mathbf{g}$, in a concentration range between $100 \mathrm{mM}$ to $20 \% \mathrm{v} / \mathrm{v}$, optimized for each nucleophile, with a selection of 3-hydroxyaldehyde electrophiles 2a,b ( $80 \mathrm{mM}$ ) (Scheme 1) using FSA D6X variants as catalysts. Electrophiles $\mathbf{2 a} \mathbf{a} \mathbf{b}$ have the advantage to shift reaction equilibrium by cyclic hemiketal formation of the product. Moreover, 2b would introduce a chiral center as internal stereochemical reference (Scheme 1). We started with 3-hydroxypropanal (2a) and the ketone nucleophiles in aqueous $50 \mathrm{mM}$ triethanolamine buffer $\mathrm{pH} 8$, similar to the conditions used in our previous communication. ${ }^{31}$ D6X variants where $\mathrm{X}=\mathrm{A}, \mathrm{T}$, or $\mathrm{H}$ were identified as the most effective ones for the addition of $\mathbf{1 b}(2.0 \mathrm{M}, 15 \% \mathrm{v} / \mathrm{v})$ to $\mathbf{2 a}$, based on TLC analysis (Table S3). Compound $\mathbf{3 b}$ was isolated in $32 \%$ yield using FSA D6H as catalyst (Scheme 1A, Table 1). No reaction was detected for the addition of $1 \mathrm{c}-\mathrm{g}$ to $2 \mathrm{a}$ with any of the FSA variants screened. Increasing the concentration of $1 \mathrm{c}-\mathrm{g}$ up to $20 \% \mathrm{v} / \mathrm{v}$, to compensate for potentially low $K_{\mathrm{M}}$ values, was unfruitful. Furthermore, in a second round of protein engineering we combined L107A, L163A, and A165G mutations with selected D6X mutations, i.e. $\mathrm{X}=\mathrm{L}, \mathrm{H}$, or $\mathrm{E}$. However, no positive hits were found (Table S3).

$(S)$-3-Hydroxybutanal ( $S$-2b) gave intense new spots on TLC in the aldol additions of: $\mathbf{1 b}(15 \% \mathrm{v} / \mathrm{v})$ using FSA D6X, where $\mathrm{X}=\mathrm{A}, \mathrm{L}, \mathrm{N}, \mathrm{Q}, \mathrm{S}, \mathrm{T}, \mathrm{E}$, and $\mathrm{H}$; $1 \mathrm{e}(5 \% \mathrm{v} / \mathrm{v})$ using FSA D6L and D6H; and 1f (5\% v/v) using FSA D6N and D6H (Table S3). The common active variant, FSA D6H, furnished $\mathbf{4 b}, \mathbf{4 e}$, and $\mathbf{4 f}$ in $25 \%, 22 \%$, and $8 \%$ isolated yields, respectively (Scheme 1B, Table 1).

(R)-3-Hydroxybutanal ( $R-2 \mathbf{b})$ was tested with $\mathbf{1 b}(15 \% \mathrm{v} / \mathrm{v})$ to check whether it was also substrate of FSA D6X catalysts. The best variant (i.e., FSA D6H) gave the expected lactol $\mathbf{5 b}$ (Scheme 1C, Table 1). However, lower yields were achieved as compared with $S-\mathbf{2} \mathbf{b}$, suggesting some degree of enantiomeric discrimination. $^{31}$

Next, we studied the addition of ethanal (1a) to electrophiles $2 \mathbf{a}, \mathbf{b}$. It was observed that test reactions carried out at $15 \%-20 \% \mathrm{v} / \mathrm{v}$ of $1 \mathrm{a}$ yielded a mixture of products arising from its nonenzymatic self-aldolization. ${ }^{36}$ It is likely that the electrophilic reactivity of $\mathbf{1 a}$ inactivated the enzyme and just 
Scheme 1. FSA Variants Catalyzed Aldol Additions of 1a-b, 1e-f to (A) 2a, (B) $S$-2b, (C) R-2b, and (D) $2 \mathrm{c}$

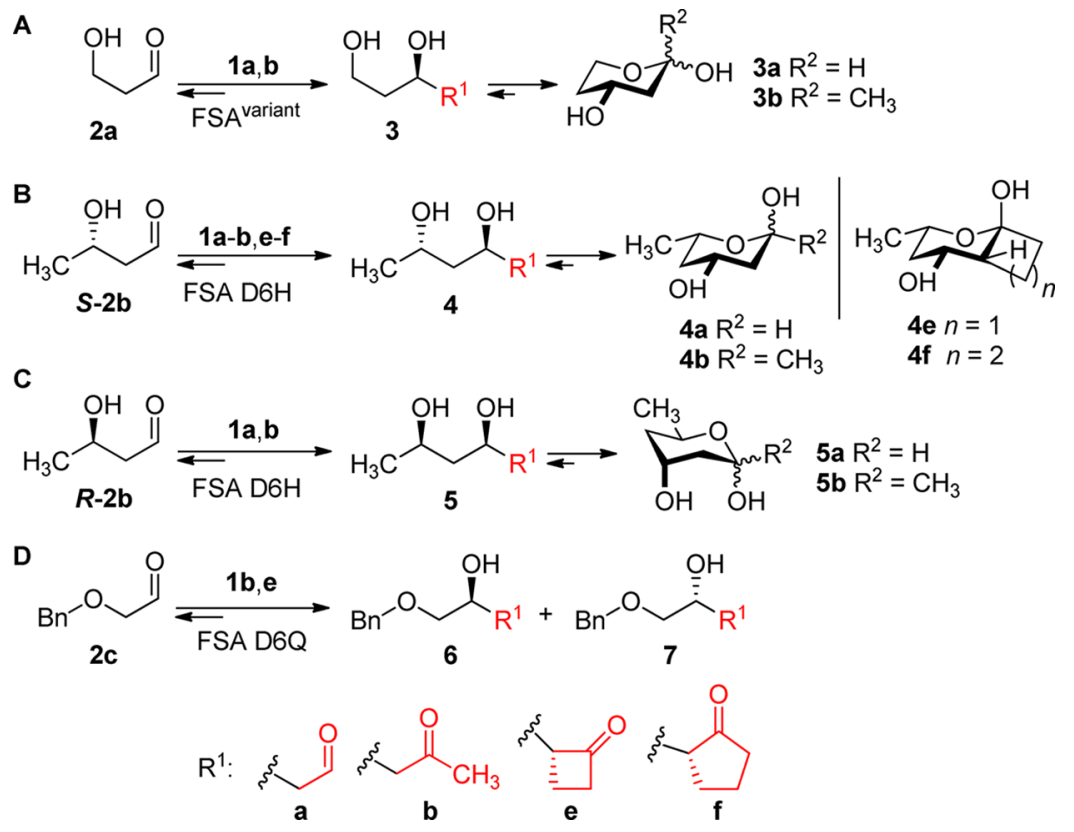

Table 1. FSA-Variant-Catalyzed Aldol Additions of 1a,b,e,f, to $2 \mathrm{a}-\mathrm{c}$

\begin{tabular}{|c|c|c|c|c|c|}
\hline $\mathrm{Nu}$ & E & FSA variant & product & isolated yield ${ }^{a} \%$ & ee or $\mathrm{dr}^{b}, \%$ \\
\hline $1 \mathrm{a}$ & $2 a$ & D6L/A165G & $3 \mathbf{a}^{c}$ & 4 & $-^{e}$ \\
\hline $1 b$ & $2 a$ & $\mathrm{D} 6 \mathrm{H}$ & $3 \mathbf{b}^{d}$ & 32 & $>95^{f}$ \\
\hline 1a & $S-2 b$ & $\mathrm{D} 6 \mathrm{H}$ & $4 a^{g}$ & 27 & $97: 3$ \\
\hline $1 b$ & $S-2 \mathrm{~b}$ & $\mathrm{D} 6 \mathrm{H}$ & $4 b$ & 25 & $97: 3$ \\
\hline $1 \mathrm{e}$ & $S-2 \mathrm{~b}$ & $\mathrm{D} 6 \mathrm{H}$ & $4 e^{h}$ & 22 & $97: 3$ \\
\hline 1f & $S-2 \mathrm{~b}$ & $\mathrm{D} 6 \mathrm{H}$ & $4 f$ & 8 & $97: 3$ \\
\hline 1a & $R-2 b$ & $\mathrm{D} 6 \mathrm{H}$ & $5 \mathbf{a}^{i}$ & 14 & $97: 3$ \\
\hline $1 b$ & $R-2 b$ & $\mathrm{D} 6 \mathrm{H}$ & $5 b$ & 13 & $97: 3$ \\
\hline $1 b$ & $2 c$ & D6Q & $6 b$ & 77 & $>98^{j}$ \\
\hline 1e & $2 c$ & D6Q & $6 e: 7 e$ & 10 & $75: 25$ \\
\hline
\end{tabular}

${ }^{a}$ Product isolation and purification procedures were devised to eliminate the unconverted starting material and collecting all potential diasteroisomers. Reaction and purification conditions were not optimized. ${ }^{b} \mathrm{dr}$ determined by NMR. ${ }^{c} \alpha: \beta$ 1:1. ${ }^{d} \alpha$ and $\beta$ anomers in equilibrium with the acyclic structure: $\alpha: \beta$ :acyclic $0.5: 0.9: 1.0 .{ }^{e}$ ee not determined, $[\alpha]_{\mathrm{D}}{ }^{20}=-2.93(c=0.62$ in $\mathrm{MeOH})$, and this was compared with the optical rotation of the product obtained using DERA $_{\text {Ecoli }}$ as catalyst: $[\alpha]_{\mathrm{D}}{ }^{20}=-28.6(c=1 \mathrm{in} \mathrm{MeOH})\left(\mathrm{Lit} . .^{3}[\alpha]_{\mathrm{D}}{ }^{20}=\right.$ $-19.0(c=0.5, \mathrm{MeOH})$ obtained using also DERA $\mathrm{Ecoli}_{\text {a }}$ as catalyst $) .{ }_{\mathrm{ee}}$ determined by chiral GC after formation of the methyl glycoside derivative against a racemic sample obtained by aldol addition of $\mathbf{1 b}$ $(80 \% \mathrm{v} / \mathrm{v})$ to $2 \mathrm{a}$ catalyzed by pyrrolidine. ${ }^{g} \alpha: \beta \quad 1: 1 .{ }^{h}$ Hemiketal:acyclic adduct ratio was $85: 15 .{ }^{i} \alpha: \beta \quad 4: 1 .{ }^{j}$ ee determined by chiral HPLC analysis. Racemic mixture obtained by chemical synthesis using LDA methodology. Nu: nucleophile; E: electrophile.

the spontaneous chemical reaction took place. Indeed, at 100 $\mathrm{mM}$ concentration of $\mathbf{1 a}$, the addition to $S$ - and $R-\mathbf{2} \mathbf{b}$ catalyzed by FSA D6H and D6N yielded the desired aldol product. The common active variant, FSA D6H, furnished $\mathbf{4 a}$ and $\mathbf{5 a}$ in $27 \%$ and $14 \%$ isolated yields, respectively (Scheme 1B,C, Table 1). In the case of $2 \mathrm{a}$, the double mutant FSA D6L/A165G was active for the addition of $1 \mathrm{a}$ at $5 \% \mathrm{v} / \mathrm{v}$, rendering $3 \mathrm{a}$ in $4 \%$ isolated yield (Table 1).

2-Hydroxyethanal was also tested as electrophile with all nucleophiles 1a-g, but it was not converted in the desired sense by any FSA variant. Thus, the $O$-protected derivative, 2-benzyloxyethanal (2c), was considered as synthetic equivalent, which we reported as a good electrophile for aldol additions of DHA and HA catalyzed by FSA. ${ }^{22,25}$ For additions to $2 \mathrm{c}, \mathrm{D} 6 \mathrm{~N}$ and $\mathrm{D} 6 \mathrm{Q}$ variants gave the highest conversions (95\%) when the electrophile was $\mathbf{1 b}(15 \% \mathrm{v} / \mathrm{v})$, whereas only FSA D6Q gave acceptable conversions (53\%) when it was 1e $(5 \% \mathrm{v} / \mathrm{v})$ (Table S3). Accordingly, FSA D6Q furnished $\mathbf{6 b}$ in $77 \%$ and $\mathbf{6 e}+7 \mathbf{e}$ in $10 \%$ isolated yields (Scheme 1D, Table 1 ). No product was formed for all other nucleophiles with any of the FSA variants.

Butanone (1c), 3-pentanone (1d), and cyclohexanone (1g) were not accepted as nucleophiles by any of the FSA variants assayed with any of the electrophiles. Most probably this is due to steric interactions that difficult a proper orientation for the electrophiles and/or the nucleophiles. It is noteworthy that 1c was tolerated as nucleophile with L-G3P electrophile; ${ }^{31}$ however the latter is one of the most reactive electrophiles, which could compensate for the lower activity of $\mathbf{1 c}$.

In none of the reactions involving 1 a as nucleophile, neither homoaldol addition nor trimerization reactions were observed. This is in contrast with what was seen with 2-deoxy-D-ribose-5phosphate aldolase Escherichia coli $\left(\mathrm{DERA}_{E c o l i}\right) .{ }^{37}$ Furthermore, no reactions were detected with any nucleophile/electrophile pair in control experiments performed with FSA wild-type and the inactive the inactive FSA K85M variant.

Stereoselectivity is an issue of paramount importance in these reactions. Formation of D-threo aldol adducts has been reported using catalysis by wild-type FSA and variants, practically irrespective of structural variations of nucleophile and electrophile. Moreover, the attack of FSA-enamine nucleophile invariably takes place from its $s i$-face, for steric reasons and with no exceptions hitherto known. 18,19,21,24,28,29

Aldol adducts $\mathbf{4 a - f}$ and $\mathbf{5 a , b}$, obtained by FSA D6H catalysis showed high diastereomeric purity (dr: 97:3, within the limits of high field NMR detection) (Table 1). The internal chiral center from electrophiles $\mathbf{2 b}$ and the formation of 6-membered ring hemiketals helped us to assign the absolute stereochemistry of the one or two newly formed 
stereocenters, which resulted to be $R$-configured, in $\mathbf{4 a , b}$ and $\mathbf{5 a}, \mathbf{b}$, and $R, R$ in $\mathbf{4} \mathbf{e}-\mathbf{f}$. Derivatives of lactol $\mathbf{5} \mathbf{a}$ are extensively used as the chiral side chain for the synthesis of statin drugs. ${ }^{37}$ The spectral data of $\mathbf{5 a}$ matched those obtained from the trimerization of acetaldehyde catalyzed by DERA Ecoli $_{\text {. Lactol 4a }}$ is the 5-epimer of 5a and may constitute also an important building block for stereochemical analogs of statins. ${ }^{38}$ Structural motives depicted in Scheme 1 are present in many natural products and synthetic intermediates. ${ }^{8}$ Furthermore, rare sugars are important for generating novel "glycolrandomized" analogues of natural products, ${ }^{5,39-41}$ in the search for improved pharmaceutical lead compounds. ${ }^{42}$

Consistent with the stereochemical outcome of adducts $4 \mathrm{e}-$ f, an $E$ configured FSA K85-enamine is imposed by the rigid ring of nucleophiles 1e and 1f (Figure 3). ${ }^{31}$ In contrast, a $Z$

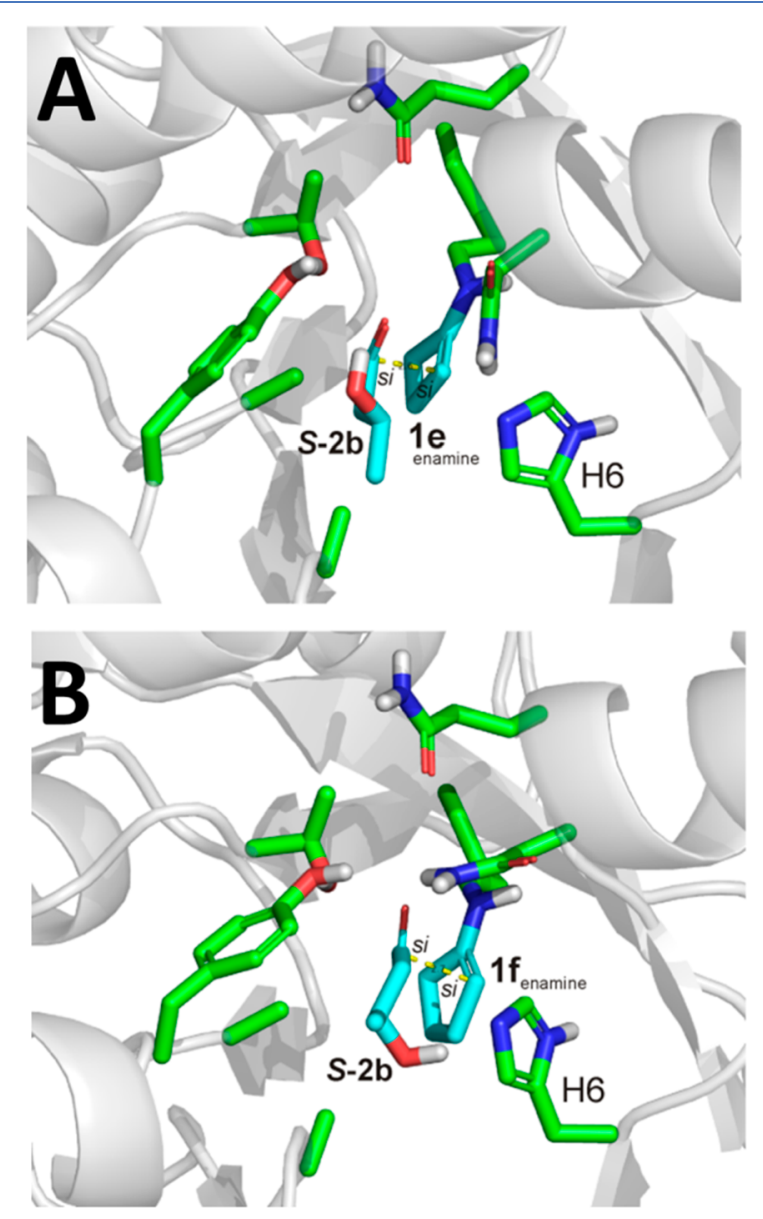

Figure 3. Molecular models of FSA-bound 1e-enamine/S-2b (A) and 1f-enamine/S-2b (B) intermediates.

configured FSA K85-enamine nucleophile is always formed with the acyclic hydroxymethylketone analogues (Figure 1A). ${ }^{17-19,28}$ In both cases, the nucleophilic attack takes place from the $s i$-face, and the $\mathrm{C}=\mathrm{O}$ of both $S$ - and $R-\mathbf{2} \mathbf{b}$ was always attacked from its si-face. Thus, the anti-configured aldol adducts were obtained with nucleophiles 1e and 1f, whereas the syn products were observed with acyclic hydroxymethylketones. The anti-stereochemistry from the addition of cyclopentanone to L-G3P catalyzed by FSA D6H, could not be unequivocally ascertained in the previous work because of the epimerization of the C- $\alpha$ to the carbonyl stereocenter under the reaction conditions. ${ }^{31}$ In the present case, the epimeriza- tion was plausibly precluded by the in situ formation of the cyclic hemiketals: for $4 \mathrm{e}$ the cyclic:acyclic ratio was $85: 15$, and for $\mathbf{4 f}$, no acyclic species were detected by NMR.

Products $\mathbf{3 b}$ and $\mathbf{6 b}$, synthesized using catalysis by FSA D6H and $\mathrm{D} 6 \mathrm{Q}$, respectively, showed high enantiomeric purity by chiral GC and HPLC analysis against racemic samples (Table 1). By analogy with $\mathbf{4 b}$, it may safely be assumed that $\mathbf{3 b}$ has the $R$ configuration, which correlates to products $\mathbf{4 a}$ and $\mathbf{5 a}, \mathbf{b}$. This is consistent with the addition of hydroxymethylketone nucleophiles to 2a catalyzed by wild-type FSA. ${ }^{17,28}$ Moreover, the optical rotation of the unprotected product $9 \mathbf{b},[\alpha]_{\mathrm{D}}{ }^{20}=$ $-30.3\left(c=0.5\right.$ in $\mathrm{CHCl}_{3}$ ) (lit.: ${ }^{43}$ for the $\mathrm{R}$ enantiomer $[\alpha]_{\mathrm{D}}{ }^{20}=$ $\left.+34.0\left(c=0.44, \mathrm{CHCl}_{3}\right)\right)$ indicated that it was the $S$ enantiomer.

The aldol addition of $1 \mathrm{e}$ to $2 \mathrm{c}$ gave a mixture of two diastereoisomers $6 \mathrm{e}: 7 \mathrm{e}$. These can arise from (i) the lack of a precise stereofacial $\mathrm{C}=\mathrm{O}$ orientation of $2 \mathrm{c}$ to the enzymeenamine complex, yielding epimers at $\mathrm{C}-\beta$ to the carbonyl, ${ }^{19,26}$ or (ii) the epimerization of the $\mathrm{C}-\alpha$ to the carbonyl group (i.e., the carbon tertiary center and in this case no hemiketal can be formed) under the reaction conditions ( $\mathrm{pH}$ 8.0). ${ }^{31}$ Since deuterium exchange at $\mathrm{C}-\alpha$ to the carbonyl group was not detected by NMR, it was concluded that products $6 \mathbf{e}$ and $7 \mathbf{e}$ were obtained via the first route.

\section{CONCLUSIONS}

We herein present FSA D6X variants that catalyze aldol additions of ethanal (1a) and simple ketones $\mathbf{1 b}, \mathbf{1 e}$, and $\mathbf{1 f}$ to nonphosphorylated hydroxyaldehydes $(\mathbf{2 c}, \mathbf{d})$. Substitution of D6 in wild-type FSA by amino acids such as $\mathrm{L}, \mathrm{N}, \mathrm{Q}, \mathrm{E}$, or $\mathrm{H}$ is critical to generate favorable interactions at the active site for nucleophile activation. It is noteworthy that different residues in this position with dissimilar electronic and steric properties, but not the native aspartate, rendered enzymes that were able to catalyze the addition. Because the isosteric neutral mutation D6N was active, aspartate appears to have a detrimental electronic effect for the addition of nonfunctionalized aliphatic ketones and ethanal to nonphosphorylated electrophilic substrates. Propanone (1b) was accepted as nucleophile component with all the selected electrophiles. Propanone is the closest analogue of hydroxypropanone, the best reported hydroxymethylketone nucleophile substrate for FSA. ${ }^{24,25,28}$ The FSA D6H variant was effective with most of the reactions, accepting structurally different nucleophiles (e.g., 1a and 1f). Since none of the nucleophiles or electrophiles studied here has equivalent hydroxyl groups to those present in hydroxyketones, which can establish hydrogen-bond interactions with residue D6 (Figure 2), it could be speculated that $\mathrm{H}$ in position 6 could have a role limiting the conformational mobility of substrates because of its larger size. This could pose a hindrance to the rotation of the $\mathrm{C}-\mathrm{N}$ enamine bond and favor an adequate orientation of the approaching acceptor carbonyl, thus favoring the reaction of selected substrates.

We demonstrate that direct biocatalytic bottom up construction of rare deoxysugars and chiral intermediates is possible by the choice of aldol components using FSA as catalyst with immediate control over sites of deoxygenation. This work, along with previous studies on FSA, has shown the unprecedented versatility of this aldolase with just minimal changes in its active site. In this sense, FSA goes far beyond any known aldolase in its breath of scope for asymmetric organic synthesis, particularly when compared with dihydroxyacetone phosphate (DHAP)-dependent aldolases and DERA 
for their narrow nucleophile selectivity. ${ }^{44-48}$ DERA is highly selective for ethanal but showed two-orders of magnitude lower activity toward ketones such as propanone and fluoropropanone. ${ }^{48}$ Further experiments to widen the synthetic scope of FSA for aldol reactions of simple aliphatic aldehydes and ketones to amino aldehydes are in progress.

\section{ASSOCIATED CONTENT}

\section{S Supporting Information}

The Supporting Information is available free of charge on the ACS Publications website at DOI: 10.1021/acscatal.8b02486.

Materials, general procedures, protein expression and purification of FSA catalysts and 2-deoxy-D-ribose-5phosphate aldolase from E. coli $\left(\mathrm{DERA}_{E c o l i}\right)$ catalyst, activity assay of FSA catalysts, preparation of racemic aldol adducts; FSA variants screening; preparative enzymatic reactions, description of physical and spectral properties and NMR spectra of the corresponding aldol adducts (PDF)

\section{AUTHOR INFORMATION}

\section{Corresponding Author \\ *E-mail for PC: pere.clapes@iqac.csic.es. \\ ORCID}

Teodor Parella: 0000-0002-1914-2709

Pere Clapés: 0000-0001-5541-4794

\section{Author Contributions}

The manuscript was written through contributions of all authors. All authors have given approval to the final version of the manuscript.

\section{Funding}

European Union's Horizon 2020 grant agreement no 635595 (CarbaZymes). Ministerio de Economia y Competitividad (MINECO) and Fondo Europeo de Desarrollo Regional (FEDER) (grant CTQ2015-63563-R to P.C. and CTQ201564436-P to T.P.). Funding from the Auvergne (France) council.

\section{Notes}

The authors declare no competing financial interest.

\section{ACKNOWLEDGMENTS}

This project has received funding from the European Union's Horizon 2020 research and innovation program under grant agreement No 635595 (CarbaZymes), the Ministerio de Economía y Competitividad (MINECO), the Fondo Europeo de Desarrollo Regional (FEDER) (grant CTQ2015-63563-R to P.C. and CTQ2015-64436-P to T.P.), COST action CM1303 Systems Biocatalysis and funding from the Auvergne council.

\section{REFERENCES}

(1) Hoffmann, R. W. Conformation Design of Open-Chain Compounds. Angew. Chem., Int. Ed. 2000, 39, 2054-2070.

(2) Fleming, I.; Ghosh, S. K. Stereocontrol in Organic Synthesis using Silicon-Containing Compounds. Syntheses of ( \pm )-2-Deoxyribonolactone and $( \pm)$-arabonolactone. J. Chem. Soc., Perkin Trans. 1 1998, 2711-2720.

(3) Liu, J. J.; Wong, C. H. Aldolase-Catalyzed Asymmetric Synthesis of Novel Pyranose Synthons as a New Entry to Heterocycles and Epothilones. Angew. Chem., Int. Ed. 2002, 41, 1404-1407.
(4) He, X. M.; Liu, H.-w. Formation of Unusual Sugars: Mechanistic Studies and Biosynthetic Applications. Annu. Rev. Biochem. 2002, 71, $701-754$.

(5) Thibodeaux, C. J.; Melançon, C. E. I.; Liu, H.-w. NaturalProduct Sugar Biosynthesis and Enzymatic Glycodiversification. Angew. Chem., Int. Ed. 2008, 47, 9814-9859.

(6) Martínez, A.; Zumbansen, K.; Döhring, A.; van Gemmeren, M.; List, B. Improved Conditions for the Proline-Catalyzed Aldol Reaction of Acetone with Aliphatic Aldehydes. Synlett 2014, 25, 932-934.

(7) Mahrwald, R.; Gündogan, B. Highly Regioselective Lewis AcidMediated Aldol Additions at the More Encumbered $\alpha$-Side of Unsymmetrical Ketones. J. Am. Chem. Soc. 1998, 120, 413-414.

(8) Schetter, B.; Mahrwald, R. Modern Aldol Methods for the Total Synthesis of Polyketides. Angew. Chem., Int. Ed. 2006, 45, 7506-7525.

(9) Scheffler, U.; Mahrwald, R. Asymmetric Organocatalyzed Direct Aldol Additions of Enolizable Aldehydes. Synlett 2011, 2011, 16601667.

(10) Northrup, A. B.; MacMillan, D. W. C. The First Direct and Enantioselective Cross-Aldol Reaction of Aldehydes. J. Am. Chem. Soc. 2002, 124, 6798-6799.

(11) Clapés, P.; Fessner, W.-D.; Sprenger, G. A.; Samland, A. K. Recent Progress in Stereoselective Synthesis with Aldolases. Curr. Opin. Chem. Biol. 2010, 14, 154-167.

(12) Dean, S. M.; Greenberg, W. A.; Wong, C.-H. Recent Advances in Aldolase-Catalyzed Asymmetric Synthesis. Adv. Synth. Catal. 2007, $349,1308-1320$

(13) Clapés, P. Enzymatic C-C Bond Formation. In Biocatalysis in Organic Synthesis; Faber, K., Fessner, W.-D., Turner, N. J., Eds.; Georg Thieme Verlag KG: Stuttgart (Germany), 2015; Vol. 2, pp 31-92.

(14) Wechsler, C.; Meyer, D.; Loschonsky, S.; Funk, L.-M.; Neumann, P.; Ficner, R.; Brodhun, F.; Müller, M.; Tittmann, K. Tuning and Switching Enantioselectivity of Asymmetric Carboligation in an Enzyme through Mutational Analysis of a Single Hot Spot. ChemBioChem 2015, 16, 2580-2584.

(15) Schürmann, M.; Sprenger, G. A. Fructose-6-Phosphate Aldolase is a Novel Class I Aldolase from Escherichia coli and is Related to a Novel Group of Bacterial Transaldolases. J. Biol. Chem. 2001, 276, 11055-11061.

(16) Güclü, D.; Szekrenyi, A.; Garrabou, X.; Kickstein, M.; Junker, S.; Clapés, P.; Fessner, W.-D. Minimalist Protein Engineering of an Aldolase Provokes Unprecedented Substrate Promiscuity. ACS Catal. 2016, 6, 1848-1852.

(17) Szekrenyi, A.; Garrabou, X.; Parella, T.; Joglar, J.; Bujons, J.; Clapés, P. Asymmetric Assembly of Aldose Carbohydrates from Formaldehyde and Glycolaldehyde by Tandem Biocatalytic Aldol Reactions. Nat. Chem. 2015, 7, 724-729.

(18) Soler, A.; Gutiérrez, M. L.; Bujons, J.; Parella, T.; Minguillon, C.; Joglar, J.; Clapés, P. Structure-Guided Engineering of D-Fructose6-Phosphate Aldolase for Improved Acceptor Tolerance in Biocatalytic Aldol Additions. Adv. Synth. Catal. 2015, 357, 1787-1807.

(19) Szekrenyi, A.; Soler, A.; Garrabou, X.; Guerard-Helaine, C.; Parella, T.; Joglar, J.; Lemaire, M.; Bujons, J.; Clapés, P. Engineering the Donor Selectivity of D-Fructose-6-Phosphate Aldolase for Biocatalytic Asymmetric Cross-Aldol Additions of Glycolaldehyde. Chem. - Eur. J. 2014, 20, 12572-12583.

(20) Soler, A.; Garrabou, X.; Hernández, K.; Gutiérrez, M. L.; Busto, E.; Bujons, J.; Parella, T.; Joglar, J.; Clapés, P. Sequential Biocatalytic Aldol Reactions in Multistep Asymmetric Synthesis: Pipecolic Acid, Piperidine and Pyrrolidine (Homo)Iminocyclitol Derivatives from Achiral Building Blocks. Adv. Synth. Catal. 2014, 356, 3007-3024.

(21) Guerard-Helaine, C.; Debacker, M.; Clapes, P.; Szekrenyi, A.; Helaine, V.; Lemaire, M. Efficient Biocatalytic Processes for Highly Valuable Terminally Phosphorylated C5 to C9 D-Ketoses. Green Chem. 2014, 16, 1109-1113.

(22) Gutierrez, M.; Parella, T.; Joglar, J.; Bujons, J.; Clapés, P. Structure-Guided Redesign of D-Fructose-6-phosphate Aldolase from E. coli: Remarkable Activity and Selectivity Towards Acceptor 
Substrates by Two-Point Mutation. Chem. Commun. 2011, 47, 57625764.

(23) Castillo, J. A.; Guérard-Hélaine, C.; Gutiérrez, M.; Garrabou, X.; Sancelme, M.; Schürmann, M.; Inoue, T.; Hélaine, V.; Charmantray, F.; Gefflaut, T.; Hecquet, L.; Joglar, J.; Clapés, P.; Sprenger, G. A.; Lemaire, M. A Mutant D-Fructose-6-Phosphate Aldolase (Ala129Ser) with Improved Affinity towards Dihydroxyacetone for the Synthesis of Polyhydroxylated Compounds. Adv. Synth. Catal. 2010, 352, 1039-1046.

(24) Garrabou, X.; Castillo, J. A.; Guérard-Hélaine, C.; Parella, T.; Joglar, J.; Lemaire, M.; Clapés, P. Asymmetric Self- and Cross-Aldol Reaction of Glycolaldehyde Catalyzed by D-Fructose-6-phosphate Aldolase. Angew. Chem., Int. Ed. 2009, 48, 5521-5525.

(25) Concia, A. L.; Lozano, C.; Castillo, J. A.; Parella, T.; Joglar, J.; Clapés, P. D-Fructose-6-Phosphate Aldolase in Organic Synthesis: Cascade Chemical-Enzymatic Preparation of Sugar-Related Polyhydroxylated Compounds. Chem. - Eur. J. 2009, 15, 3808-3816.

(26) Castillo, J. A.; Calveras, J.; Casas, J.; Mitjans, M.; Vinardell, M. P.; Parella, T.; Inoue, T.; Sprenger, G. A.; Joglar, J.; Clapés, P. Fructose-6-Phosphate Aldolase in Organic Synthesis: Preparation of D-Fagomine, N-Alkylated Derivatives, and Preliminary Biological Assays. Org. Lett. 2006, 8, 6067-6070.

(27) Fessner, W. D.; Heyl, D.; Rale, M. Multi-Enzymatic Cascade Synthesis of D-Fructose 6-Phosphate and Deoxy analogs as Substrates for High-Throughput Aldolase Screening. Catal. Sci. Technol. 2012, 2, 1596-1601.

(28) Rale, M.; Schneider, S.; Sprenger, G. A.; Samland, A. K.; Fessner, W.-D. Broadening Deoxysugar Glycodiversity: Natural and Engineered Transaldolases Unlock a Complementary Substrate Space. Chem. - Eur. J. 2011, 17, 2623-2632.

(29) Hélaine, V.; Mahdi, R.; Sudhir Babu, G. V.; de Berardinis, V.; Wohlgemuth, R.; Lemaire, M.; Guérard-Hélaine, C. Straightforward Synthesis of Terminally Phosphorylated L-Sugars via Multienzymatic Cascade Reactions. Adv. Synth. Catal. 2015, 357, 1703-1708.

(30) Sanchez-Moreno, I.; Helaine, V.; Poupard, N.; Charmantray, F.; Legeret, B.; Hecquet, L.; Garcia-Junceda, E.; Wohlgemuth, R.; Guerard-Helaine, C.; Lemaire, M. One-Pot Cascade Reactions using Fructose-6-phosphate Aldolase: Efficient Synthesis of D-Arabinose 5Phosphate, D-Fructose 6-Phosphate and Analogues. Adv. Synth. Catal. 2012, 354, 1725-1730.

(31) Roldán, R.; Sanchez-Moreno, I.; Scheidt, T.; Hélaine, V.; Lemaire, M.; Parella, T.; Clapés, P.; Fessner, W.-D.; Guérard-Hélaine, C. Breaking the Dogma of Aldolase Specificity: Simple Aliphatic Ketones and Aldehydes are Nucleophiles for Fructose-6-phosphate Aldolase. Chem. - Eur. J. 2017, 23, 5005-5009.

(32) Junker, S.; Roldan, R.; Joosten, H.-J.; Clapés, P.; Fessner, W.-D. Complete Switch of Reaction Specificity of an Aldolase by Directed Evolution In Vitro: Synthesis of Generic Aliphatic Aldol Products. Angew. Chem., Int. Ed. 2018, 57, 10153-10157.

(33) Lehwess-Litzmann, A.; Neumann, P.; Parthier, C.; Lüdtke, S.; Golbik, R.; Ficner, R.; Tittmann, K. Twisted Schiff Base Intermediates and Substrate Locale Revise Transaldolase Mechanism. Nat. Chem. Biol. 2011, 7, 678-684.

(34) Stellmacher, L.; Sandalova, T.; Leptihn, S.; Schneider, G.; Sprenger, G. A.; Samland, A. K. Acid-Base Catalyst Discriminates between a Fructose 6-Phosphate Aldolase and a Transaldolase. ChemCatChem 2015, 7, 3140-3151.

(35) Tittmann, K. Sweet Siblings with Different Faces: The Mechanisms of FBP and F6P Aldolase, Transaldolase, Transketolase and Phosphoketolase Revisited in Light of Recent Structural Data. Bioorg. Chem. 2014, 57, 263-280.

(36) Castañar, L.; Roldán, R.; Clapés, P.; Virgili, A.; Parella, T. Disentangling Complex Mixtures of Compounds with Near-Identical $1 \mathrm{H}$ and 13C NMR Spectra using Pure Shift NMR Spectroscopy. Chem. - Eur. J. 2015, 21, 7682-7685.

(37) Gijsen, H. J. M.; Wong, C.-H. Unprecedented Asymmetric Aldol Reactions with Three Aldehyde Substrates Catalyzed by 2-Deoxyribose-5-Phosphate Aldolase. J. Am. Chem. Soc. 1994, 116, $8422-8423$.
(38) Muller, M. Chemoenzymatic Synthesis of Building Blocks for Statin Side Chains. Angew. Chem., Int. Ed. 2005, 44, 362-365.

(39) Thibodeaux, C. J.; Melancon, C. E.; Liu, H.-w. Unusual Sugar Biosynthesis and Natural Product Glycodiversification. Nature (London, U. K.) 2007, 446, 1008-1016.

(40) Luzhetskyy, A.; Mendez, C.; Salas, J. A.; Bechthold, A. Glycosyltransferases, Important Tools for Drug Design. Curr. Top. Med. Chem. 2008, 8, 680-709.

(41) Mendez, C.; Luzhetskyy, A.; Bechthold, A.; Salas, J. A. Deoxysugars in Bioactive Natural Products: Development of Novel Derivatives by Altering The Sugar Pattern. Curr. Top. Med. Chem. 2008, 8, 710-724.

(42) Newman, D. J.; Cragg, G. M.; Snader, K. M. Natural Products as Sources of New Drugs over the Period 1981-2002. J. Nat. Prod. 2003, 66, 1022-1037.

(43) Li, D. R.; Murugan, A.; Falck, J. R. Enantioselective, Organocatalytic Oxy-Michael Addition to $\gamma / \delta$-Hydroxy- $\alpha, \beta$-enones: Boronate-Amine Complexes as Chiral Hydroxide Synthons. J. Am. Chem. Soc. 2008, 130, 46-48.

(44) Arth, H. L.; Fessner, W.-D. Practical Synthesis of 4-Hydroxy-3Oxobutylphosphonic Acid and its Evaluation as a Bio-Isosteric Substrate of DHAP Aldolase. Carbohydr. Res. 1997, 305, 313-321.

(45) Fessner, W.-D.; Sinerius, G. Enzymes in Organic Synthesis. 7. Synthesis of Dihydroxyacetone Phosphate (and Isosteric Analogs) by Enzymic Oxidation: Sugars from Glycerol. Angew. Chem., Int. Ed. Engl. 1994, 33, 209-212.

(46) Garrabou, X.; Joglar, J.; Parella, T.; Crehuet, R.; Bujons, J.; Clapés, P. Redesign of the Phosphate Binding Site of L-Rhamnulose-lPhosphate Aldolase towards a Dihydroxyacetone Dependent Aldolase. Adv. Synth. Catal. 2011, 353, 89-99.

(47) Garrabou, X.; Calveras, J.; Joglar, J.; Parella, T.; Bujons, J.; Clapés, P. Highly Efficient Aldol additions of DHA and DHAP to $\mathrm{N}$-Cbz-Amino aldehydes Catalyzed by L-Rhamnulose-1-Phosphate and L-Fuculose-1-Phosphate Aldolases in Aqueous Borate Buffer. Org. Biomol. Chem. 2011, 9, 8430-8436.

(48) Chen, L.; Dumas, D. P.; Wong, C.-H. Deoxyribose 5-Phosphate Aldolase as a Catalyst in Asymmetric Aldol Condensation. J. Am. Chem. Soc. 1992, 114, 741-748. 